Cell Research (2001); 11(4): 301-310

http://www.cell-research.com

\title{
Function of GATA transcription factors in hydroxyurea-induced HEL cells
}

\author{
ZHANG Shu Bing, Qi Ye HE, Hui ZHAO, Chang Yun GUI, Chu JIANG, Ruo Lan QIAN* \\ Institute of Biochemistry and Cell Biology, Shanghai Institutes for Biological Sciences, Chinese Academy of \\ Sciences, 320 Yueyang Road, Shanghai 200031, China.
}

\begin{abstract}
HEL cells, a human erythroleukemia cell line, mainly express the fetal $(\gamma)$ globin gene and trace amount of the embryonic $(\varepsilon)$ globin gene, but not adult $(\beta)$ globin gene. Here we show that hydroxyurea (HU) can induce HEL cells to express adult $(\beta)$ globin gene and lead these cells to terminal differentiation. Results showed in Gel mobility shift assays that GATA factors could specifically bind to the regulatory elements of human b- globin gene, including the proximal regulatory element (the $\beta$-promoter) and the distal regulatory elements (the DNase I hypersensitive sites in the LCR, HS2-HS4 core sequences). However, the DNA binding patterns of GATA factors were quite different between HU-induced and uninduced HEL cells. Western-blot analysis of nuclear extracts from both the uninduced and HU- induced HEL cells revealed that the level of GATA-2 transcription factor decreased, whereas the level of GATA-1 transcription factor increased following the time of hydroxyurea induction. Furthermore, using RT-PCR analysis the expression of human $\beta$-globin gene in HU-induced HEL cells could be blocked again when HEL cells were incubated in the presence of antisense oligonucleotides for hGATA-1, suggesting that the upregulation of hGATA-1 transcription factor might be critical for the expression of human $\beta$-globin gene in HU-induced HEL cells.
\end{abstract}

Key words: GATA transcription factors, human $\beta$-globin gene, HEL cells, hydroxyurea.

\section{INTRODUCTION}

Hydroxyurea has been shown to increase the production of fetal hemoglobin $(\mathrm{HbF})$ in some patients with sickle cell anemia and $\beta$-thalassemia[1], [2]. However, the molecular mechanisms by which the expression of globin gene is activated and regulated are poorly understood.

The Zinc-finger protein GATA-1 is a lineagespecific transcription factor. It is expressed at high levels in erythroid precursors, megakaryocytes , mast

\footnotetext{
* Corresponding author: Prof. Ruo Lan QIAN, e-mail: qianlab@sunm.shcnc.ac.cn, Tel: 0086-21-643-15030-2092, Fax: 0086-21-643-31090

Abbreviation used: HU, hydroxyurea.

Received Aug-13-2001 Revised Nov-6-2001 Accepted Nov-20-2001
}

cells and eosinophils[3-6], and at lower level in multipotential progenitors [7-9]. While GATA-2 is expressed in a large number of different cell types, including hematopoietic stem cell, multipotential progenitors, mast cells and endothelial cells[9-10]. Both GATA-1 and GATA-2 can bind to the consensus sequence (T/A)GATA(A/G) with high affinity. The GATA motifs are widely present in the regulatory regions of the human $\beta$-globin gene cluster, including promoters, enhancers and the globin locus control region LCR. These results only provide an indirect evidence that the interactions between GATA factors and GATA motifs may play an important role in regulating the expression of globin genes and cell differentiation. However, it is of interest to reveal how the GATA factors regulate the expression of globin genes during cell differentiation. In 
this study we use HEL cells as a model to reveal the molecular mechanisms involved in erythroid-specific gene expression and cell differentiation. Our results show that human $\beta$-globin gene can be expressed in HEL cells induced by hydroxyurea and that GATA1may play an important role in stimulating the expression of human $\beta$-globin gene in HU-induced HEL cells and cell differentiation. While GATA-2 may probably inhibit the differentiation of HEL cells.

\section{MATERIALS AND METHODS}

\section{Cell culture}

HEL cells were maintained in RPMI-1640 medium (GIBCOBRL) supplemented with $10 \%$ newborn calf serum, penicillin (50 $\mu \mathrm{g} / \mathrm{ml})$, streptomycin $(100 \mu / \mathrm{ml})$ and glutamine $(300 \mu \mathrm{g} / \mathrm{ml})$. HEL cells were induced by hydroxyurea (Sigma) at the final concentration of $150 \mu \mathrm{M}$ for $24 \mathrm{~h}$.

\section{The preparation of nuclear protein and total cell extracts}

For total cell extracts, cells were lysed in lysis buffer $(50 \mathrm{~m}$ M TRIS, pH 7.4; 100m M DTT; 1\%NP-40; $10 \%$ glycerol; 2m M phenylmethane-sulfonylfluoride, PMSF). Cell lysates were clarified by centrifugation for $10 \mathrm{~min}$ at $10000 \mathrm{rpm}$ at $4^{\circ} \mathrm{C}$. Nuclear extracts from both the HU-induced and un-induced HEL cells were prepared as described previously[11], [12]. The protein concentration was determined according to Bradfords' s method [13].

\section{Gel mobility shift assay}

Gel mobility shift assays were performed as described previously[14]. The competitive DNA fragments were synthesized by Shanghai Institute of Cell Biology, Chinese Academy of Sciences. The synthesized oligonucleotides used in this study are as follows:

(1) The competitor with GATA motif:

$$
\begin{aligned}
& \text { 5' -CACTTGATAACAGAAAGTGATAACTCT-3, } \\
& \text { 3' -GTGAACTATTGTCTTTCACTATTGAGA-5' }
\end{aligned}
$$

(2) The competitor with CACCCC motif:

$$
\text { 5' -CTGACCCCACCCCACCCT-3, }
$$$$
\text { 3' - GACTGGGGTGGGGTGGGA-5' }
$$

(3) The YY-1 competitor:

5' -CGCTCCGCGGCCATCTTGGCGGCTGGT-3'

3' -GCGAGGCGCCGGTAGAACCGCCGACCA-5'

The GATA-1 and GATA-2 specific antibodies used in the supershift assays were obtained from Santa Cruz Biotechnology Co. For each sample, $10 \mathrm{mg}$ of nuclear extracts was preincubated with $2 \mathrm{mg}$ antibody for $1 \mathrm{~h}$ at $4^{\circ} \mathrm{C}$ prior to incubation with the $[\gamma$ $\left.{ }^{32} \mathrm{P}\right] \mathrm{ATP}$-labeled probe for $1 \mathrm{~h}$ at $4^{\circ} \mathrm{C}$ and electrophoresis. Dried gels were exposed to X-ray film for $1-2$ days at $-80^{\circ} \mathrm{C}$.

\section{Preparation of DNA probes}

The promoter of human b-globin gene (+20 -112 bp), HS2 core sequence (-10681 -10971 bp), 3' flanking sequence of HS2 core sequence (-10323 -10680 bp), HS3 core sequence (-14991 -
$14716 \mathrm{bp}$ ) and HS4 core sequence (-18586 -18306 bp) were cloned respectively and prepared with restriction enzymes. These probes were labeled with (g-32P)-ATP for Gel mobility shift assays .

\section{Western blot analysis}

For Western blotting, protein samples separated on SDSPAGE gels were blotted to nitrocellulose membranes. The membranes were then blocked with $1 \%$ BSA in washing buffer $(10 \mathrm{~m} \mathrm{M}$ Tris.HCl pH 7.6, $150 \mathrm{~m} \mathrm{M} \mathrm{NaCl}$ and 0.1\% Tween-20) for $2 \mathrm{~h}$, incubated with monoclonal antibodies specific for GATA-1 or GATA-2 (1:5000 dilution of whole serum) for $2 \mathrm{~h}$, washed with washing buffer for 3 times, incubated with HRP-labeled secondary antibodies (1:200 dilution) for $2 \mathrm{~h}$, washed with washing buffer for 3 times. Finally the membranes were detected with ECL (Amersham).

\section{RT-PCR analysis}

The following sense and antisense -oligonucleotides for hGATA1 and hGATA-2 were synthesized: Sense for hGATA-1, GAGGCTCCATGGAGTTCC; antisense for hGATA-1, GGAACTCCATGGAGCCTC; sense for hGATA-2, GGCCGGCCATGGAGGTGG and antisense for hGATA-2, CCACCTCCATGGCCGGCC. Synthetic oligonucleotides $(5 \mu \mathrm{M})$ were incubated with HEL cells either in the presence of hydroxyurea $(150 \mu \mathrm{M})$ or in the absence of hydroxyurea for $48 \mathrm{~h}$ at $37^{\circ} \mathrm{C}$. After incubation, total RNA was prepared and RT-PCR assays were performed as described previously[15].

\section{RESULTS}

Identification of the expression of human $\beta$-globin gene in HEL cells induced by hydroxyurea

HEL cells, a human erythroleukemia cell line, express mainly the $\gamma$-globin genes, small amount of

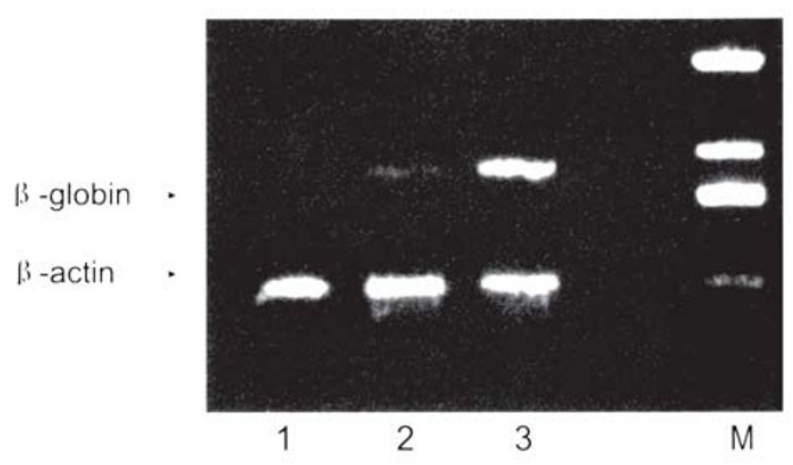

Fig 1. RT-PCR analysis of human $\beta$-globin gene expression in both the HU-induced and un- induced HEL cells Lane 1: HEL cells were cultured without the induction of $\mathrm{HU}$; Lane 2: HEL cells were cultured with $150 \mu \mathrm{M}$ of $\mathrm{HU}$ for 12 h; Lane 3: HEL cells were cultured with $150 \mu \mathrm{M}$ of HU for 24 h; Lane M: Molecular weight marker. 
$\varepsilon$-globin gene, but not $\beta$-globin gene. RT-PCR analyses demonstrated that human $\beta$-globin gene was expressed in HEL cells induced by Hydroxyurea $(150 \mu \mathrm{M})$ for 12, $24 \mathrm{~h}$ (Fig 1, lanes 2-3). In addition, b- globin gene expression could not be detected in un-induced HEL cells (Fig 1, lane 1). It is of interest to investigate why HU can induce the expression of human $\beta$-globin gene in HEL cells and how the erythroid -specific trans-acting factors play their roles. Is GATA-1 transcription factor necessary for human $\beta$-globin gene switching in HEL cells?

Characterization of trans-acting factors binding to the proximal control element of human $\beta$-globin gene (the $\beta$-Promoter)

In order to clarify the molecular mechanisms involved in the expression of human $\beta$-globin gene in HU-induced HEL cells, The binding of nuclear proteins isolated from both the HU-induced and uninduced HEL cells to the $\beta$-promoter $(+20 \sim$ $112 \mathrm{bp}$ ) was tested by gel mobility shift assays. One shift band (A) could be detected with nuclear extracts from un-induced HEL cells (Fig 2, Lanes 2, 3 and Fig 3, Lane 2). While, the intensity of band A was dramatically decreased and a new band (B) could be detected with nuclear extracts from HU-induced HEL cells (Fig 2, Lanes 4, 5 and Fig 3, Lane5). Gel shift competition analysis was performed using two

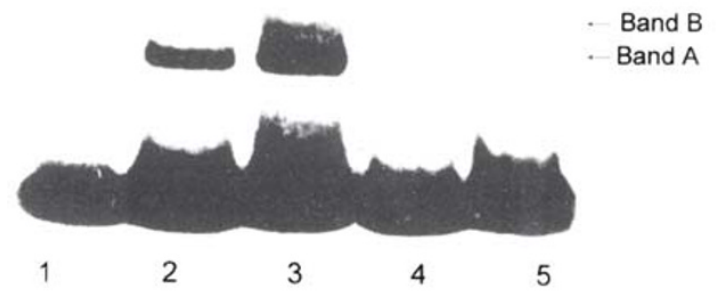

Fig 2. The binding patterns between the promoter of human $\beta$-globin gene and the nuclear extracts from both the HUinduced and un-induced HEL cells

The promoter of human $\beta$-globin gene $(+20 \sim-112 \mathrm{bp})$ was 5 'end labeled . Lane1: Labeled probe incubated without any protein; Lanes 2-3: Labeled probe incubated with $1 \mu \mathrm{g}$ and 2 $\mu \mathrm{g}$ of nuclear extracts from un-induced HEL cells respectively; Lanes 4-5: Labeled probe incubated with $1 \mu \mathrm{g}$ and $2 \mu \mathrm{g}$ of nuclear extracts from HU-induced HEL cells respectively. oligonucleotides containing GATA-binding site or CACCC binding motif. As can be seen in Fig 3, both bands (A and B) couldn' t be competed by CACCC competitor (Fig 3, Lanes 3,6) and could be competed by GATA competitor (Fig 3, Lanes 4, 7), indicating that both bands (A, B) belong to GATA factors.

Characterization of trans-acting factors binding to the DNaseI hypersensitive sites (HS2-HS4 Core DNA sequences) in the LCR

The locus control region (LCR) is characterized by at least five DNase 1 hypersensitive sites (HS1HS5) distributed over $20 \mathrm{~Kb} 5$ ' of the $\beta$ globin gene and has been found to be essential for high level, tissue-specific globin gene expression. It may also play an important role in hemoglobin switching through the interaction of trans-acting factors with local cis-acting elements. Therefore, the interactions between the DNase 1 hypersensitive sites (HS2 HS4 core sequences) and nuclear proteins isolated from both the HU-induced and un-induced HEL cells were also examined. We first pay attention to the HS2 core DNA sequence (-10681 -10971 bp) because HS2 functions as a typical enhancer. To identify the nuclear proteins binding to the HS2 core

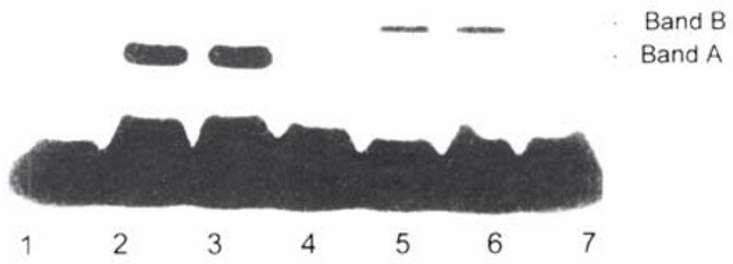

Fig 3. Competitive EMSA

The promoter of human $\beta$-globin gene $(+20 \sim-112 \mathrm{bp})$ was $5^{\prime}$ end labeled. Lane1: Labeled probe incubated without any protein; Lane2: Labeled probe incubated with $2 \mathrm{mg}$ of nuclear extracts from un-induced HEL cells; Lanes 3-4: Labeled probe incubated with $2 \mu \mathrm{g}$ of nuclear extracts from un-induced HEL cells in the presence of 100-fold excess of both unlabelled CACCC and GATA competitors respectively; Lane5: Labeled probe incubated with $2 \mu \mathrm{g}$ of nuclear extracts from HUinduced HEL cells; Lanes 6-7: Labeled probe incubated with $2 \mu \mathrm{g}$ of nuclear extracts from HU-induced HEL cells in the presence of 100-fold excess of both unlabelled CACCC and GATA competitors respectively. 
DNA sequence, gel mobility shift assays were performed in which this DNA fragment was used as a probe. With the nuclear extracts from uninduced

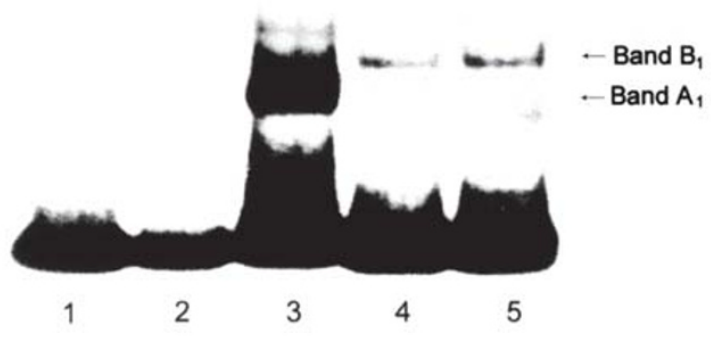

Fig 4. The binding patterns between HS2core and nuclear extracts from both the HU-induced and un-induced HEL cells

The HS2core DNA fragment (-10681 -10971 bp) was 5' end labeled. Lane 1: Labeled probe incubated without any protein; Lanes 2-3: Labeled probe incubated with $1 \mu \mathrm{g}$ and 2 $\mu \mathrm{g}$ of nuclear extracts from un-induced HEL cells respectively; Lanes 4-5: Labeled probe incubated with $1 \mu \mathrm{g}$ and $2 \mu \mathrm{g}$ of nuclear extracts from HU-induced HEL cells respectively.

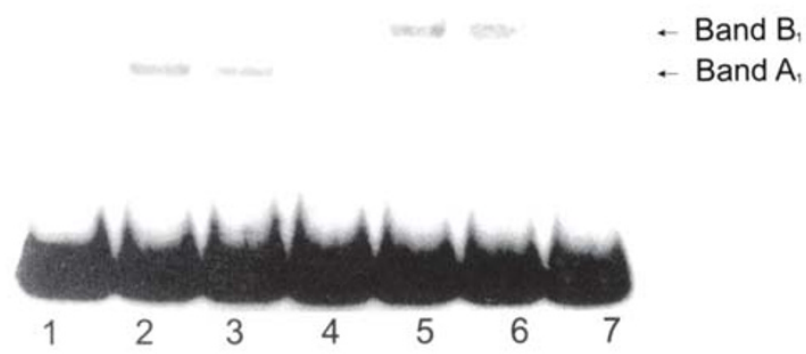

Fig 5. Competitive EMSA

The HS2core DNA fragment (-10681 -10971 bp) was 5' end labeled. Lane 1: Labeled probe incubated without any protein; Lane 2: Labeled probe incubated with $2 \mathrm{mg}$ of nuclear extracts from un-induced HEL cells; Lane 3: Labeled probe incubated with $2 \mu \mathrm{g}$ of nuclear extracts from un-induced HEL cells in the presence of 100- fold excess of unlabelled CACCC oligonucleotide as a competitor; Lane 4: Labeled probe incubated with $2 \mu \mathrm{g}$ of nuclear extracts from un-induced HEL cells in the presence of 100- fold excess of unlabelled GATA oligonucleotide as a competitor. Lane 5: Labeled probe incubated with $2 \mu \mathrm{g}$ of nuclear extracts from HU-induced HEL cells; Lane 6: Labeled probe incubated with $2 \mathrm{mg}$ of nuclear extracts from HU-induced HEL cells in the presence of 100fold excess of unlabelled CACCC oligonucleotide as a competitor; Lane 7: Labeled probe incubated with $2 \mu \mathrm{g}$ of nuclear extracts from HU-induced HEL cells in the presence of 100- fold excess of unlabelled GATA oligonucleotide as a competitor.
HEL cells only one band (A1) was observed (Fig 4, Lane 3). However, the intensity of band A1 was decreased and a new band (B1) could be seen with nuclear extracts from HU-induced HEL cells (Fig 4, Lanes 4, 5), competitive gel mobility shift assay revealed that both bands (A1 and B1) were competed by GATA competitor (Fig 5, Lanes 4 and 7) but not by CACCC competitor (Fig 5, Lanes 3 and 6 ).

Furthermore, only one band (A2) was detectable with nuclear extracts from uninduced HEL cells when the 3' flanking sequence of HS2 core DNA sequence (-10323 bp -10680 bp) was used as a probe (Fig 6, Lanes 2 and 3). However, no band could be seen with nuclear extracts from HU-induced HEL cells (Fig 6, Lanes 4 and 5). Meantime, competitive Gel mobility shift assay was carried out. Band A2 couldn't be competed by CACCC competitor and could be competed by GATA competitor (Fig 7, Lanes 3 and 4). We suggest that erythroid-specific factors (bands A1, A2 and B1) binding to HS2 core sequence and the 3' -flanking sequence of HS2 core DNA sequence might be GATA factors.

To determine whether the HS3 and HS4 core sequences $(-14991 \sim-14716 \mathrm{bp}$ and $-18586 \sim$ $18306 \mathrm{bp}$ ) also participate in regulating the expression of human $\beta$-globin gene in HU-induced HEL cells, the Gel mobility shift assays were also performed. The binding pattern of nuclear proteins to

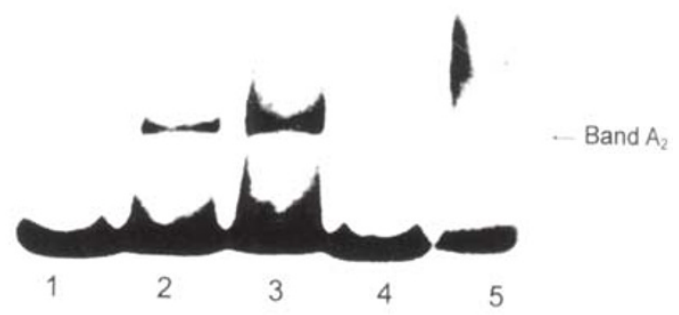

Fig 6. The binding pattern between 3 ' flanking sequence of HS2core and nuclear extracts from both the HU-induced and un-induced HEL cells

The 3' -flanking DNA sequence of HS2core (-10323 -10680 bp) was 5' end labeled. Lane 1: Labeled probe incubated without any protein; Lanes 2-3: Labeled probe incubated with $1 \mathrm{mg}$ and $2 \mathrm{mg}$ of nuclear extracts from un-induced HEL cells respectively; Lanes 4-5: Labeled probe incubated with $1 \mathrm{mg}$ and $2 \mu \mathrm{g}$ of nuclear extracts from HU-induced HEL cells respectively. 
the HS3 core sequence is very similar to that of the HS4 core sequence. Only one shift band (A3) was visible with nuclear extracts from un-induced HEL cells (Fig 8 Lane 2 and Fig 9, Lane 2). This band was competed by the GATA competitor (Fig 8, Lane

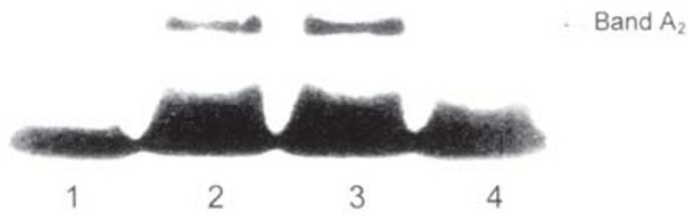

Fig 7. Competitive EMSA

The 3' flanking sequence of HS2core ( -10323 -10680 bp) was 5'end labeled. Lane 1: Labeled probe incubated without any protein; Lane 2 : Labeled probe incubated with $2 \mathrm{mg}$ of nuclear extracts from un-induced HEL cells; Lane 3: Labeled probe incubated with $2 \mu \mathrm{g}$ of nuclear extracts from un-induced HEL cells in the presence of 100-fold excess of unlabelled CACCC oligonucleotide as a competitor; Lane 4: Labeled probe incubated with $2 \mu \mathrm{g}$ of nuclear extracts from un-induced HEL cells in the presence of 100- fold excess of unlabelled GATA oligonucleotide as a competitor.

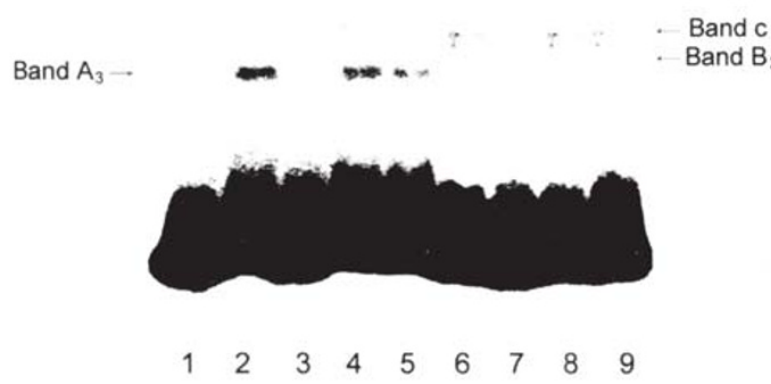

Fig 8. The binding pattern between HS3 core DNA sequence and nuclear extracts from both the HU- induced and uninduced HEL cells

The HS3 core DNA sequence (-14991 -14716 bp) was 5' end labeled. Lane 1: Labeled probe incubated without any protein; Lane 2: Labeled probe incubated with $1 \mu \mathrm{g}$ of nuclear extracts from un-induced HEL cells; Lanes 3-5: Labeled probe incubated with $1 \mathrm{mg}$ of nuclear extracts from un-induced HEL cells in the presence of 200 folds excess of unlabelled competitors (GATA, YY-1 and CACCC double stranded DNA respectively); Lane 6: Labeled probe incubated with $1 \mu \mathrm{g}$ of nuclear extracts from HU-induced HEL cells; Lanes 7-9: Labeled probe incubated with $1 \mu \mathrm{g}$ of nuclear extracts from HU-induced HEL cells in the presence of 200 folds excess of unlabeled competitors (GATA,YY-1 and CACCC double stranded DNA respectively).
3 and Fig 9, Lane 3), but not by both CACCC and YYcompetitors (Fig 8 , Lanes 4, 5 and Fig 9, Lanes 4, 5). Moreover, we observed in the Gel mobility shift assay that the band A3 couldn' $t$ be visible and two new bands (B2 and C) could be revealed with nuclear proteins isolated from HU-induced HEL cells (Fig 8, Lane 6 and Fig 9, Lane 6). Both bands (B2, C) were competed by GATA competitor ( Fig 8, Lane 7 and Fig 9, Lane 7), but not by both CACCC and YY1 competitors (Fig 8, Lanes 8, 9 and Fig 9, Lanes 8, 9), suggesting that both bands (B2, C) are GATA factors. It seems that sequences in the HS3 and HS4 cores may participate in regulating the expression of human $\beta$-globin gene through interaction with GATA factors.

To further investigate whether GATA-1 factor up-regulation is critical in the induction of human $\beta$ globin gene expression in HU-induced HEL cells, supershift analyses using antibody specific to GATA1 or GATA-2 factor were carried out. We used the synthsized oligonucleotide containing the consensus

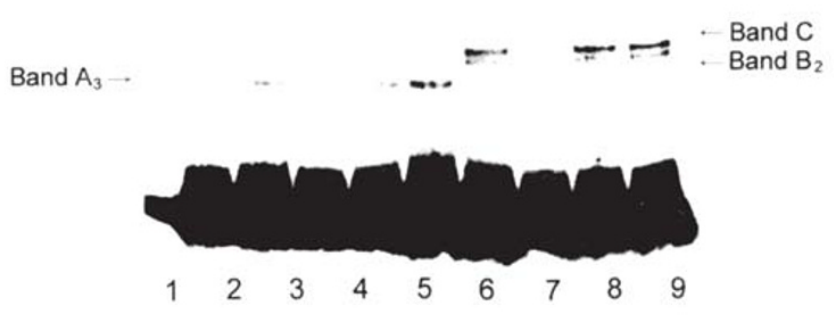

Fig 9. The binding pattern between HS4 core DNA sequence and nuclear extracts from both the HU- induced and uninduced HEL cells

The HS4core DNA sequence (-18586 -18306 bp) was 5' end labeled. Lane 1: Labeled probe incubated without any protein; Lane 2: Labeled probe incubated with $1 \mu \mathrm{g}$ of nuclear extracts from un-induced HEL cells; Lanes 3-5: Labeled probe incubated with $1 \mu \mathrm{g}$ of nuclear extracts from un-induced HEL cells in the presence of 200 fold excess of unlabeled competitors (GATA, YY-1 and CACCC double stranded DNA respectively); Lane 6: Labeled probe incubated with $1 \mathrm{mg}$ of nuclear extracts from HU-induced HEL cells; Lanes 7-9: Labeled probe incubated with $1 \mathrm{mg}$ of nuclear extracts from HU-induced HEL cells in the presence of 200 fold excess of unlabeled competitors (GATA,YY-1 and CACCC double stranded DNA respectively). 
binding sites for GATA factors as a probe. In EMSAs, A major shift band (D) could be detected with nuclear extracts from un-induced HEL cells (Fig 10, Lane 2). Although supershift band couldn't be detectable, the band $\mathrm{D}$ was partially competed for DNA binding by using monoclonal antibody specific to GATA-2 (Fig 10, Lane 4), while it couldn't be competed by monoclonal antibody specific to GATA1 (Fig 10, Lane 3). Furthermore, using nuclear extracts from HU-induced HEL cells we also detected one shift band (E) (Fig 10, Lane 5), which was partially competed for DNA binding by antibody specific to GATA-1 (Fig 10, Lane 6), but not by monoclonal antibody specific to GATA-2 (Fig 10, Lane 7). Data showed that DNA binding activity was decreased apparently when the GATA-1 and GATA-2 transcription factors were specifically recognized by and combined with their antibodies.

The levels of GATA factors (GATA-1 and GATA-2) is changeable in HEL cells following the induction of hydroxyurea

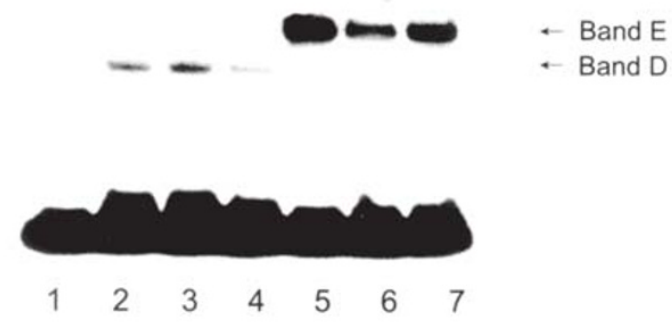

Fig 10. Supershift analysis: Nuclear extracts were prepared from both the un-induced and HU-induced HEL cells and were incubated with antibodies specific to GATA-1 and GATA2 respectively. The probe containing GATA consensus binding motifs was synthsized.

Lane 1: Labeled probe incubated without any protein; Lane 2: Labeled probe incubated with $10 \mu \mathrm{g}$ of nuclear extracts from un-induced HEL cells; Lane 3: Labeled probe incubated with $10 \mu \mathrm{g}$ of nuclear extracts from un-induced HEL cells in the presence of $2 \mu \mathrm{g}$ antibody specific to GATA-1; Lane 4: Labeled probe incubated with $10 \mu \mathrm{g}$ of nuclear extracts from un-induced HEL cells in the presence of $2 \mu \mathrm{g}$ antibody specific to GATA-2; Lane 5: Labeled probe incubated with $10 \mathrm{mg}$ of nuclear extracts from HU-induced HEL cells; Lane 6: Labeled probe incubated with $10 \mu \mathrm{g}$ of nuclear extracts from HU-induced HEL cells in the presence of $2 \mu \mathrm{g}$ antibody specific to GATA-1; Lane 7: Labeled probe incubated with 10 $\mu \mathrm{g}$ of nuclear extracts from HU-induced HEL cells in the presence of $2 \mu \mathrm{g}$ antibody specific to GATA-2.
To investigate the changes in the levels of GATA1 and GATA-2 transcription factors in both the HUinduced and un-induced HEL cells, western blot assays using GATA-1 and GATA-2 monoclonal antibodies were performed. Results showed that the level of GATA-1 transcription factor in the nuclear proteins of HEL cells increased following the time of hydroxyurea induction (Fig 11, Lanes 2-4), while the level of GATA-2 transcription factor decreased (Fig 12, Lanes 2-4), indicating that different GATA family members may play distinct roles in the regulation of $\beta$-like globin genes expression through the selective interaction with the regulatory elements

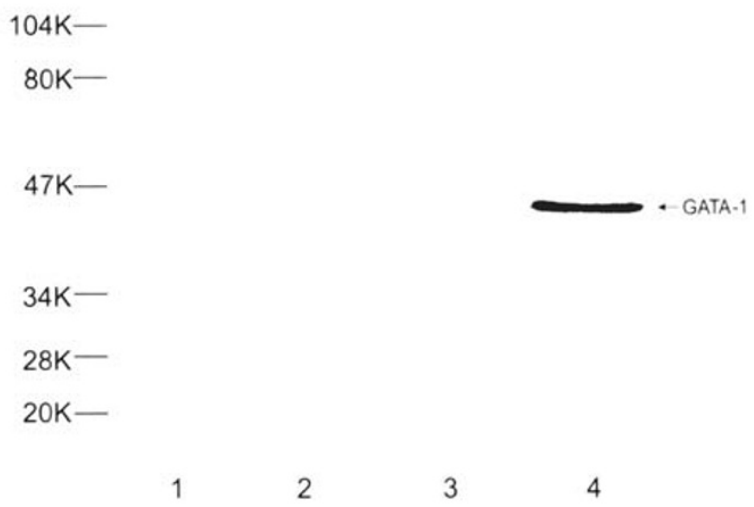

Fig 11. Western blotting assay

The nuclear extracts from both the HU-induced and uninduced HEL cells were prepared. The monoclonal antibody of GATA-1 was used. Lane 1: $40 \mu \mathrm{g}$ of nuclear proteins from un-induced HEL cells; Lanes 2-4: $40 \mu \mathrm{g}$ of nuclear proteins from HEL cells induced by using $150 \mu \mathrm{M}$ of HU for 2, 12, and $24 \mathrm{~h}$ respectively.

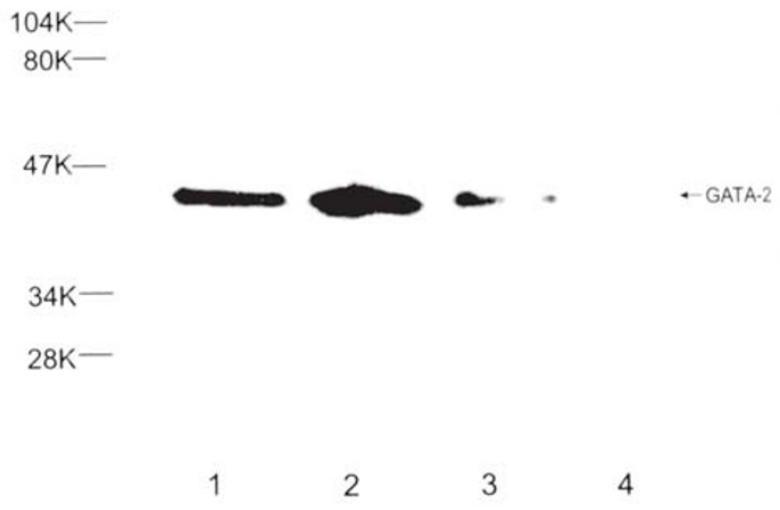

Fig 12. Western blotting assay

The nuclear extracts from both the HU-induced and uninduced HEL cells were prepared. The monoclonal antibody of GATA-2 was used.

Lane 1: $40 \mu \mathrm{g}$ of nuclear proteins from un-induced HEL cells; Lanes 2-4: $40 \mu \mathrm{g}$ of nuclear proteins from HEL cells induced by using $150 \mu \mathrm{M}$ of $\mathrm{HU}$ for 2,12 , and $24 \mathrm{~h}$ respectively. 
(including proximal and distal control regions) during development. The expression and activity of different GATA family members may decide the fate of HEL cells.

The transcription factor GATA-1 Is responsible for the expression of human $\beta$-globin gene in $H U$-induced HEL cells

To further identify the effects of hGATA factors on the expression of human $\beta$-globin gene in HEL cells, The sense and antisense oligonucleotides for hGATA factors (hGATA-1 and hGATA-2) were synthesized. Western-blot analysis with nuclear extracts isolated from HU-induced HEL cells was carried out. Our results revealed that the level of hGATA-1 factor was decreased when HEL cells was incubated with antisense nucleotide for hGATA-1 (Fig 13a, Lane 1), while no change was detected with sense oligonucleotides for hGATA-1 (Fig 13a, Lane 2 ). These data also demonstrated that hGATA-1 factor activity correlated with the expression of human $\beta$-globin gene in $\mathrm{Hu}$ - induced HEL cells. In addition, western-blot assay with nuclear extract prepared from un-induced HEL cells revealed that the level of hGATA-2 protein was decreased, when HEL cells were incubated with antisense oligonucleotide for hGATA-2 (Fig 13b, Lane 2), whereas the level of hGATA2 protein was unchanged with the sense oligonucleotide for hGATA-2 (Fig 13b, Lane 3).

Using RT-PCR analysis, data showed that the human $\beta$-globin gene couldn' $\mathrm{t}$ be expressed in uninduced HEL cells (Fig 14, Lane 1). While it could (a)

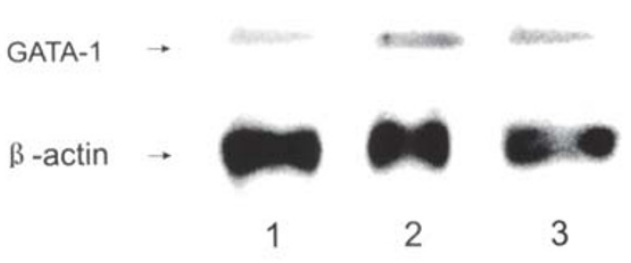

(b)

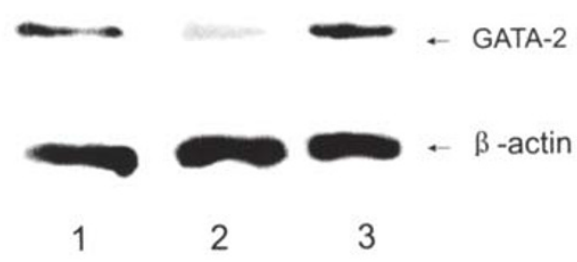

Fig 13. The western blotting assays

The total proteins from both the HU-induced and un-induced HEL cells were prepared. The monoclonal antibodies of GATA1 and GATA-2 were used. $\beta$-actin was used as internal control.

(a) Lane 1: $200 \mu \mathrm{g}$ of total proteins from HEL cells cultured with antisense oligonucleotide of hGATA1 (10 $\mu$ M) and HU(150 $\mu \mathrm{M}$ ) for $24 \mathrm{~h}$ at $37^{\circ} \mathrm{C}$; Lane 2: $200 \mu \mathrm{g}$ of total proteins from HEL cells cultured with sense oligonucleotide of hGATA1 (10 $\mu \mathrm{M})$ and $\mathrm{HU}(150 \mu \mathrm{M})$ for $24 \mathrm{~h}$ at $37^{\circ} \mathrm{C}$; Lane 3: $200 \mu \mathrm{g}$ of total proteins from HU-induced HEL cells. (b) Lane 1: $200 \mu \mathrm{g}$ of total proteins from un-induced HEL cells; Lane 2: $200 \mu \mathrm{g}$ of total proteins from HEL cells cultured with antisense oligonucleotide of hGATA2 $(10 \mu \mathrm{M})$ for $24 \mathrm{~h}$ at $37^{\circ} \mathrm{C}$ in the absence of HU; Lane 3: $200 \mu \mathrm{g}$ of total proteins from HEL cells cultured with sense oligonucleotide of hGATA2 $(10 \mathrm{~m} \mathrm{M})$ for $24 \mathrm{~h}$ at $37^{\circ} \mathrm{C}$ in the absence of HU.

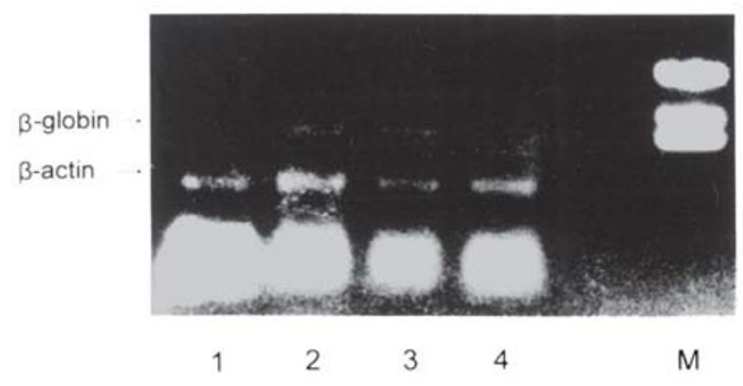

Fig 14. The effects of treatment with sense and antisense oligonucleotides for hGATA1 on the expression of human bglobin gene in HU-induced HEL cell

Cells were incubated with HU $(150 \mu \mathrm{M})$ and sense (or antisense) oligonucleotide of hGATA1 $(5 \mu \mathrm{M})$ for $48 \mathrm{~h}$ at $37^{\circ} \mathrm{C}$. RT-PCR analysis was carried out.

Lane 1: HEL cells were cultured without HU; Lane 2: HEL cells were induced with HU $(150 \mu \mathrm{M})$ for $48 \mathrm{~h}$; Lane 3: HEL cells were cultured with $\mathrm{HU}(150 \mu \mathrm{M})$ and sense oligonucleotide of hGATA1 $(5 \mu \mathrm{M})$ for $48 \mathrm{~h}$ at $37^{\circ} \mathrm{C}$; Lane 4 : HEL cells were cultured with $\mathrm{HU}(150 \mathrm{~m} \mathrm{M})$ and antisense oligonucleotide of hGATA1 ( $\mu \mathrm{M}$ ) for $48 \mathrm{~h}$ at $37^{\circ} \mathrm{C}$. 


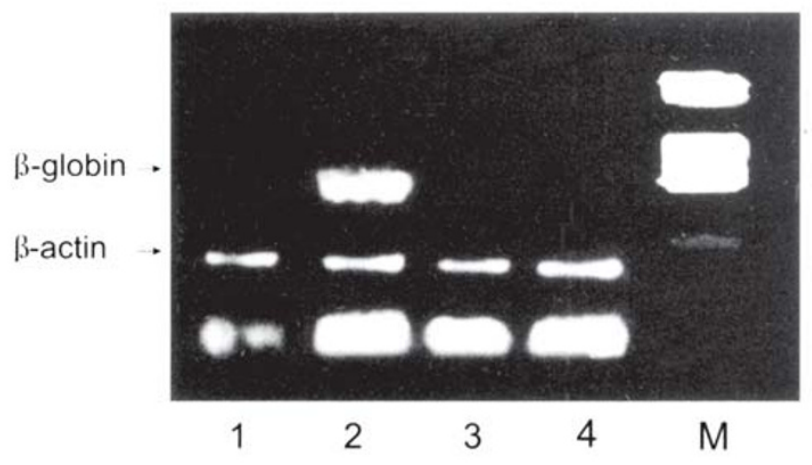

Fig 15. The effects of treatment with sense and antisense oligonucleotides for hGATA2 on the expression of human $\beta$ globin gene in un-induced HEL cells

Cells were incubated with sense or antisense oligonucleotide of hGATA2 $(5 \mu \mathrm{M})$ for $48 \mathrm{~h}$ at $37^{\circ} \mathrm{C}$ in the absence of $\mathrm{HU}$.

Lane 1: HEL cells were cultured without HU; Lane 2: HEL cells were induced with HU (150m M) for $48 \mathrm{~h}$; Lane 3 : HEL cells were cultured with sense oligonucleotide of hGATA2 (5 $\mu \mathrm{M})$ for $48 \mathrm{~h}$ at $37^{\circ} \mathrm{C}$ in the absence of HU; Lane4: HEL cells were cultured with antisense oligonucleotide of hGATA2 $(5 \mu$ M) for $48 \mathrm{~h}$ at $37^{\circ} \mathrm{C}$ in the absence of $\mathrm{HU}$.

be expressed in HU- induced HEL cells (Fig 14, Lane 2). Furthermore, antisense oligonucleotide for hGATA-1 could block the expression of human bglobin gene in HU-induced HEL cells (Fig 14, Lane 4 ), suggesting that hGATA-1 really play a key role in the expression of human $\mathrm{b} \beta$-globin gene. Meantime, There was no detectable effects on the expression of human $\beta$-globin gene with sense oligonucleotide for hGATA-1in HU-induced HEL cells (Fig 14, Lane 3). In addition, both sense and antisense oligonucleotides for hGATA-2 couldn' t induce the expression of human b-globin gene in un-induced HEL cells (Fig 15, Lanes 3, 4). Our data showed that hGATA-2 factor might be unresponsive to the expression of human $\beta$-globin gene in HEL cell.

These results further confirm that different members of hGATA factors may play different roles during the differentiation of erythrocytes. hGATA-1 may stimulate the expression of human $\beta$-globin gene and lead HEL cells to terminal differentiation. While, hGATA-2 may be related to the expression of embryonic globin genes and cell proliferation.

\section{DISCUSSION}

The human b-like globin gene cluster contains five developmentally regulated genes in the order $5^{\prime} \varepsilon, \mathrm{G} \gamma, \mathrm{A} \gamma, \delta, \beta$, which are successively expressed as the site of erythropoiesis shift during development. The entire region is controlled by the locus control region (LCR) located 6-22 Kb upstream of $\beta$-globin gene. The LCR is characterized by five DNase 1 hypersensitive sites (HS1-HS5)[16-19]. It has been shown that LCR may play an important role in the regulationof developmental stage-specific $\beta$-globin gene expression and that the expression of human b-like globin genes may be cooperatively regulated by the 5' -flanking cis-acting elements, locus control region (LCR) and erythroid specificfactors[20-22].

Both GATA-1 and GATA-2 are lineagespecificfactors. Knockouts of the lineage-restricted transcription factors lead to a selective loss of the relevant hematopoietic lineage in the animal, Gene targeting in embryonic stem cells and mice has demonstrated that GATA-1 is essential for maturation of erythroid precursors, and megakaryocytes[23-25]. GATA-1-embryos die by $\sim$ E10.5 due to extreme anemia. While GATA-2 null cells exhibit a broad hematopoietic deficit[26],[27]. Although the technique of gene knockout has provided a very useful tool to study the function of lineage-specific factor, some limitations still exist. If loss of function blocks lineage selection or maturation at an early stage, the study of later developmental events is compromised. In addition, the precise molecular mechanisms by which these regulatory events are achieved remain to be defined. Recent evidence revealed the effects of over-expression of GATA transfactors on endogenous globin genes in the stably transfected K562 cell lines: GATA-1 could decrease the expression of GATA-2 and $\varepsilon$-globin genes, while GATA-2 could increase the expression of $\gamma$-and $\varepsilon$-globin genes and has no effect on GATA-1[28].

HEL cells, a human erythroleukemia cell line, mainly express fetal $(\gamma)$ globin gene and trace amount of the embryonic ( $\varepsilon$ ) globin gene, but not the adult ( $\beta$ ) globin gene. We have used HEL cells as a model to elucidate the molecular mechanisms of globin gene expression in these cells. Our data demonstrate that treatment of HEL cells with hydroxyurea leads to the expression of human $\beta$-globin gene. Of particular interest are the trans-acting factors regulating the expression of human $\beta$-globin gene during the induction of hydroxyurea. Using western blot assay, we demonstrated that the expression of GATA-1 gene was upregulated, whereas the expression of GATA-2 gene was gradually down- 
regulated following the time of $\mathrm{HU}$-induction. Based on both the competitive EMSA and the western blot assay, our data revealed that the nuclear protein made from uninduced HEL cells, which could specifically bind to the proximal regulatory element (the $\beta$-promoter) and the distal regulatory elements (including HS2, HS3 and HS4 core sequences) of human $\beta$-globin gene, was mainly GATA-2. However, the nuclear protein isolated from HU-induced HEL cells, which could specifically bind to the $\beta$-promoter and HSs (HS2, HS3 and HS4 core sequences) in the LCR, was mainly GATA-1, indicating that the selective interactions between regulatory elements (including proximal and distal control regions ) of human $\beta$-globin gene and GATA transcription factors (GATA-1 and GATA-2) might play an important role in the regulation of human $\beta$-globin gene expression in HEL cells. In addition, two GATA factors detected in the nuclear proteins from HU-induced HEL cells, binding to both the HS3 and HS4 core DNA sequences, were mainly GATA-1 and GATA-X (a kind of unknown GATA factor). We suggest that GATA-X may activate the expression of human b-globin gene as GATA-1 in HU-induced HEL cells. It appears that the core sequences of HSs (HS2, HS3 and HS4 ) in the LCR cooperate with the proximal $\beta$-promoter, to activate and maintain the expression of human $\beta$-globin gene through interaction with GATA-1 factor in HU-induced HEL cells, meantime, the structure of chromatin in the LCR or the $\beta$-promoter may exhibit changeable active patterns (including the array of nucleosomes, the binding of transcription factors to nuclear matrix and chromatin remodeling activities).

In addition, further evidence was provided by using antisense hGATA-1 oligonuclotides, which could block the expression of human b-globin gene again in HU-induced HEL cells, suggesting that hGATA-1 factor might play a critical role in the expression of human $\beta$-globin gene in these cells. Furthermore, Previous studies have been shown that HS3 may be related to the regulation of $\varepsilon$-globin gene expression during the embryonic period, while HS4 may play a major role in the expression of bglobin gene[29]. However, our data show that HS3 may be also related to the expression of human bglobin gene in HU-induced HEL cells.

Taken together, the results presented here should provide some important clue to the molecular mechanisms involved in regulating of the expression of human $\beta$-globin gene in HEL cells. Our data suggest that GATA-1 transcription factor may play a central role in the expression of $\beta$-globin gene in HU-induced HEL cells and leads these cells to terminal differentiation. While, hGATA-2 may be related to the expression of embryonic globin genes and cell proliferation.

\section{ACKNOWLEDGEMENTS}

This work was supported by the National Natural Science Foundation of China (Grant No. 39893320 and 39870378) and the Foundation of the Chinese Academy of Sciences (Grant No. KJ982-J1-618).

\section{REFERENCES}

[1] Rodgers GP, Dover GJ, Noguchi CT, Schechter AN, Nienhuis AW. Hematologic responses of patients with sickles cell disease to treatment with hyroxyurea. N Engl J Med 1990; 322:1037-45.

[2] Huang SZ, Ren ZR, Chen MJ, Xu HP, Zeng YT, Rodgers GP, Zeng FY, Schechter AN. Treatment of b-thalassemia with hydroxyurea (Hu). Science in China 1994; 37:1350-9.

[3] Zon LI, Yamaguchi Y, Yee K, Albee EA, Kimura A,Bennett JC,Orkin SH, and Ackerman,SJ. Expression of mRNA for the GATA-binding protein in human eosinophils and basophils: potential role in gene transcription. Blood 1993; 81:3234-41.

[4] Romeo PH, Prandini MH, Joulin V, Mignotte V, Prenant, M, Vainchenker W, Marguerie G, Uzan G. Megakaryocytic and erythocytic lineages share specific transcription factors. Nature (London) 1990; 344:447-9.

[5] Martin DI, Zon LI, Mutter G, Orkin SH. Expression of an erythroid transcription factor in megakaryocytic and mast cell lineages. Nature(London) 1990; 344:444-7.

[6] Yamamoto M, Ko LJ, Leonard MW, Beug H, Orkin SH, Engel JD. Activity and tissue specific expression of the transcription factor NF-E1 multigene family. Genes Dev 1990; 4:1650-62.

[7] Sposi NM, Zon LI, Care A, Valtieri M, Testa U, Gabbianelli M, Mariani G, Bottero L, Mather,C., Orkin, S.H., and Feschle,C. Cell-cycle dependant initiation and lineagedependent abrogation of GATA-expression in pure differentiating hematopoietic progenitors. Proc Natl Acad Sci USA 1992; 89:6353-7.

[8] Leonard M, Brice M, Engel JD, Papayannopoulou T. Dynamics of GATA transcription factor expression during erythroid differentiation. Blood 1993; 82:1071-9.

[9] Wilson DB, Dorfman DM, OrkinSH. A non erythroid GATAbinding protein is required for function of the human preproendothelin-1 promoter in endothelial cells. Mol Cell Biol 1990; 10:4854-62.

[10] Zon LI, Mather C, Burgess S, Bolce ME, Harland RM, Orkin SH. Expression of GATA-binding proteins during embryonic development in Xenopus laevis. Proc Natl 
Acad Sci USA 1991; 88:10642-6.

[11] Dignam JD, Lebovitz RM, Roeder RG. Accurate transcription initiation by RNA polymeraseII in a soluble extract from isolated mammalian nuclei. Nucleic Acids Res 1983; 11:1475-89.

[12] Ausubel FM, Brent R, Kingston RE. Preparation of Nuclear and cytoplasmic extracts from mammalian cells. Short protocols in molecular Biology. 2 nd edition. New Yark: John Wiley and Sons press.1992.

[13] Bradford MM A rapid and sensitive method for the quantiation of microgram quantities of protein utilizing the principle of protein-dye binding. Anal Biochem 1976; 76:248-54.

[14] Yan ZJ, Chen YD, Qian RL. Development stage-specific factors in the mouse hematopoietic tissues binding to the 5' -flanking cis-acting elements of human $\varepsilon$-globin gene. Chinese Science Bulletin 1995; 40:778-83.

[15] Huang SZ, Rodgers GP, Zeng FY, Zeng YT, Schechter AN. Diagnosis of thalassemia using cDNA amplification of circulating erythroid cell mRNA with the polymerase chain reaction. Blood 1991; 78:2433-7.

[16] Grosveld F, van Assendelft GB, Greaves DR, KolliasG. Position-independent, high-level expression of the human beta-globin gene in transgenic mice. Cell 1978; 51: 975-85.

[17]Dhar V, Nandi A, Schildkraut CL, Skoultchi AI. Erythroidspecific nuclease-hypersensitive sites flanking the human beta-globin domain. Mol Cell Biol 1990; 10:4324-33.

[18]Orkin, SH. Regulation of globin gene expression in erythroid cells. Eur J Biochem 1995; 231:271-81.

[19] Li Q, Stamatoyannopoulos G. Hypersensitive site 5 of the human beta locus control region functions as a chromatin insulator. Blood 1994; 84:1399-401.
[20] Stamatoyannopoulos, G. Human hemoglobin switching. Science 1991; 252:383.

[21] Felsenfeld G. Chromatin as an essential part of the transcriptional mechanism. Nature 1992; 355:219-24.

[22]Tang Y, Qian RL. HS3 of the mouse $\beta$ LCR. Chinese Science Bulletin 1997; 42:2090-3.

[23] Pevny L, Simon, M C, Robertson E, Klein WH, Tsai SF, D' Agati V, Orkin SH, Costantini F. Erythroid differentiation in chimaeric mice blocked by a targeted mutation in the gene for transcription factor GATA-1. Nature (London) 1991; 349:257-60.

[24] Fujiwara Y, Browne CP, Cunniff K, Goff SC, Orkin SH. Arrested development of embryonic red cell precursors in mouse embryos lacking transcription factor GATA-1. Proc Natl Acad Sci USA 1996; 93:12355-8.

[25] Weiss, MJ, Keller G, Orkin SH. Novel insights into erythroid development revealed through in vitro differentiation of GATA-1 embryonic stem cells. Genes Dev 1994; 8:1184-97.

[26] Tsai FY, Keller G, Kuo FC, Weiss M, Chen JZ, Rosenblatt, M, Alt FW, Orkin SH. An early haematopoietic defect in mice lacking the transcription factor GATA-2. Nature 1994; 371:221-226.

[27] Tsai FY, Orkin SH. Transcription factor GATA-2 is required for proliferation/survival of early hematopoietic cells and mast cell formation, but not for erythroid and myeloid terminal differentiation. Blood 1997; 89: 3636-43.

[28] Ikonomi P, Noguchi CT, Miller W, Kassahun H, Hardison R, Schechter AN. Levels of GATA-1/GATA-2 transcription factors modulate expression of embryonic and fetal hemoglobins. Gene 2000; 261:277-87.

[29] Fraser P, Pruzina S, Antoniou M, Grosveld F. Each hypersensitive site of the human $\beta$-globin locus control region confers a different developmental pattern of expression on the globin genes. Genes Dev 1993; 7:106-13. 